\section{Elastic stockings effect on leg volume variability in healthy workers under prolonged gravitational gradient exposure}

\author{
Mirko Tessari, Sergio Gianesini, \\ Erica Menegatti, Michele Zuolo, \\ Anna Maria Malagoni, \\ Maria Elena Vannini, Paolo Zamboni \\ Vascular Diseases Center, University \\ of Ferrara, Italy
}

\section{Abstract}

The aim of this study was to determine the elastic stockings effect on healthy workers (HW) who are exposed to a prolonged hydrostatic pressure overload for professional reasons. The cohort was composed by $20 \mathrm{HW}$ who voluntarily underwent a water plethysmography test before and after eight hour of standing up in an operating room, wearing elastic stockings. After $8 \mathrm{~h}$ of gravity exposure, we demonstrated the absence of leg volume increase in case of elastic stockings use. In the morning measurement we found that the lower limb volume was $1967.5 \mathrm{~mL} \pm 224$, while in the evening it was $1962.5 \mathrm{~mL} \pm 227 \quad(\mathrm{P}<0.0828)$. The decreased volume is significantly correlated with the time that was spent under gravity forces for working purpose wearing elastic stockings $\left(\mathrm{R}^{2}=0.99, \mathrm{P}<0.0001\right)$. Our experiment demonstrates that elastic stockings may effectively counteract the increased leg volume over time in workers who are exposed to prolonged gravitational gradient. Further longitudinal studies are needed to determine if the above effect could correct one of the major risk factors for the development of chronic venous insufficiency.

\section{Introduction}

Chronic venous insufficiency (CVI) of the lower limbs is very common in the developed countries and leads to a considerable morbidity. Established risk factors for CVI include older age, female gender, geographic factors, pregnancy, family history of venous disease, obesity and work in orthostatic position. In particular, an association between CVI and prolonged standing has been reported. ${ }^{1-6}$

The common experience of legs that swell at the end of a working day is the result of a physiologic phenomenon. It is caused by extravasation of fluid from the venules because of a steadily increased venous pressure in the dependent regions of the body. ${ }^{7}$ Some studies showed that healthy workers who stood for prolonged periods during their working day had significantly higher levels of reactive oxygen species after work than controls. ${ }^{8}$

Elastic stockings compression therapy was first introduced in the fifties: it remains the most widely accepted treatment of CVI. ${ }^{9}$ Particularly, by means of air plethysmography a significant improvement of venous functional parameters with elastic stockings has been demonstrated. ${ }^{10}$

Looking at the literature, good evidences for the use of compression can be found for some clinical indications, even if little is known about the specific dosimetry, timing and type of compression to be applied. ${ }^{11}$ Although it is generally accepted that therapeutic outcomes are directly related to the quality of compression therapy, delivering precise and sustained compression therapy is an ongoing challenge for healthcare professionals..$^{12,13}$

A meta-analysis suggests that leg compression at a pressure of $10-15 \mathrm{mmHg}$ is an effective treatment for venous disorders. ${ }^{14}$ Another study reported that legs edema is a physiological phenomenon occurring after long periods of sitting and standing. Knee-length compression stockings exerting a pressure range of 11$21 \mathrm{mmHg}$ can reduce evening edema. ${ }^{15,16}$

The aim of the present study is to objectively assess by means of water plethysmography (WP) the physiological lower limbs volume changes during an ordinary surgery day in healthy physician wearing elastic stockings.

\section{Materials and Methods}

\section{Study population}

The study took place in a period of three months. The evaluated population was constituted by 20 healthy workers (HW), who were previously screened for the absence of either CVI or evident subcutaneous edema by validated clinical and ultrasonographic criteria. ${ }^{17,18}$

Particularly, duplex protocol to assess absence of reflux and/or obstruction in the great and small saphenous veins, as well as in the main deep veins, was used to exclude CVI. ${ }^{19-21}$

Even if according to the most recent guidelines a lymphoscintigraphy is requested to exclude lymphedema, not considering ethical to perform an invasive test on healthy cases we used high resolution B-mode imaging of soft tissue to detect eventual subcutaneous edema, as an exclusion factor. ${ }^{22-24}$

The group was composed by practitioner surgeons, 10 females and 10 males, who voluntarily underwent the tests, before and after 8 standing still working hours in the operating
Correspondence: Mirko Tessari, University of Ferrara, via Aldo Moro 8, 44124 Cona (FE), Italy. E-mail: mirko.tessari@unife.it

Key words: Edema; posture; gravity; water plethysmography; elastic stockings; hydrostatic pressure.

Contributions: MMT, design, data acquisition, analysis and interpretation, drafting and final approval; SG, drafting, data acquisition, analysis and interpretation, revision and final approval; EM, MZ, MEV, data acquisition and final approval; AMM, data acquisition, analysis and interpretation and final approval; PZ, design, analysis and interpretation, revision and final approval.

Conflict of interest: Vascular diseases Center of the University of Ferrara, chaired by Paolo Zamboni MD, received a research grant by New Medical Service, Italy.

Received for publication: 30 March 2015.

Revision received: 20 May 2015.

Accepted for publication: 28 May 2015.

This work is licensed under a Creative Commons Attribution 3.0 License (by-nc 3.0).

(C) Copyright M. Tessari et al., 2015

Licensee PAGEPress, Italy

Veins and Lymphatics 2015; 4:5182

doi:10.4081/vl.2015.5182

room, all performing the same long surgery procedure, wearing stockings exerting 23-28 $\mathrm{mmHg}$ of pressure at the ankle.

Four consecutive measurements of the same patient leg were performed by two different observers, showing a very low intra-individual variability (1.3\%). Overall, $320 \mathrm{WP}$ measurements were carried out for each observer. The mean age was $28.6 \pm 3.2$ years old.

\section{Leg volume assessment}

The WP permits the foot, ankle and calf volume measurement. Thirteen liters of water are poured into the WP with reference points at every $50 \mathrm{~mL}$. The water temperature ranged between $28-30^{\circ} \mathrm{C}$ and was monitored by an electrical thermometer. This temperature was higher than the $27-28^{\circ} \mathrm{C}$ proposed by Thulesius, in order to better exclude cutaneous venomotor responses. ${ }^{25}$

The WP is tall $40 \mathrm{~cm}$ and the container is all filled up till the marked level. Subsequently, the $3000 \mathrm{~mL}$ transparent container is placed under the draining spout in order to contain the water that will leak once the lower limb will be inserted into the instrument. The subject slowly inserts the foot into the water inside the WP until putting the foot sole on the base of the instrument. The subject has to maintain a 
sitting posture of $90^{\circ}$ between the thigh and the leg so that that the latter is perpendicular to the base of the WP.

Once the leg has been inserted inside the device, the exceeding water discharge is expected at the blowhole spout where the 3000 $\mathrm{mL}$ transparent container was previously placed. The collected water volume will give the measurement of the same inserted leg volume and will be expressed in milliliters. These values were reported in a database. The assessment were consecutively repeated for three times for the left limb and three times for the right limb for each subject for reproducibility assessment. During the examination the patient is asked not to move in order to allow water level stabilization. The measurements duration is approximately $15 \mathrm{~min}$ for each subject.

\section{Experiment in workers who were exposed to a prolonged gravita- tional gradient with elastic stock- ings}

The 20 HW cohort was previously screened for comorbidities. Then they underwent leg volume assessment at 7.00 a.m., immediately after their arrival at the hospital. Subsequently, they had been working for 8 hours in the operating room, in a condition of prolonged standing posture with elastic stockings. Right after, they underwent WP once again at 3.00 p.m. All the measurements were performed right outside the operating room with the same temperature $\left(23^{\circ} \mathrm{C}\right)$.

\section{Elastic stockings material}

In this study a below-knee tubular graduated elastic stocking in both legs was used. These elastic stockings are composed by $75 \%$ polyamide and $25 \%$ elastam. The compression class was $23-28 \mathrm{mmHg}$ of pressure at the ankle.

\section{Statistical analysis}

The data were analyzed with the program INSTAT 03 for Macintosh and are expressed as mean \pm standard deviation, median and interquartile range (IQR). For the statistical comparison of the different measurements the paired T-Student test was used. The linear regression analysis between time and leg volume was performed with the Pearson test. $\mathrm{P}$ values $<0.05$ have been considered significant.

\section{Results}

The right lower limb baseline volume was $1970 \mathrm{~mL} \pm 221.5$ (median 1925; IQR 275.0) and resulted to be totally comparable with the left leg volume $1965 \mathrm{~mL} \pm 233.5$ (median 1950; IQR
$362.5)$. The volume ranged from $1650 \mathrm{~mL}$ to the maximum volume of $2400 \mathrm{~mL}$.

In the measurement after $8 \mathrm{~h}$ of standing wearing elastic stockings, the two limbs volumes were respectively $1962.5 \mathrm{~mL} \pm 220.6$ (median 1925; IQR 312.5) for the right leg and $1957.5 \mathrm{~mL} \pm 239.7$ (median 1925; IQR 362.5) for the left leg. The minimum volume was 1600 $\mathrm{mL}$ and the maximum volume was $2400 \mathrm{~mL}$.

The difference between both the right and the left limbs in the morning and the same limb after the prolonged gravitational exposure was $7.5 \mathrm{~mL}$ in both legs. This is not statistically significant in according to the T-Student test $\mathrm{P}<0.08$ (Figures 1 and 2 ).

Moreover, the variation of fluids decrease in the venous-lymphatic compartment results to linearly and correlate with the time that was spent under gravity forces for working purpose wearing elastic stockings, with a high significance $\left(\mathrm{R}^{2}=0.99, \mathrm{P}<0.0001\right)$.

Figures 3 and 4 clearly show the legs volume

\section{LL Right Standing with Elastic Stockings}

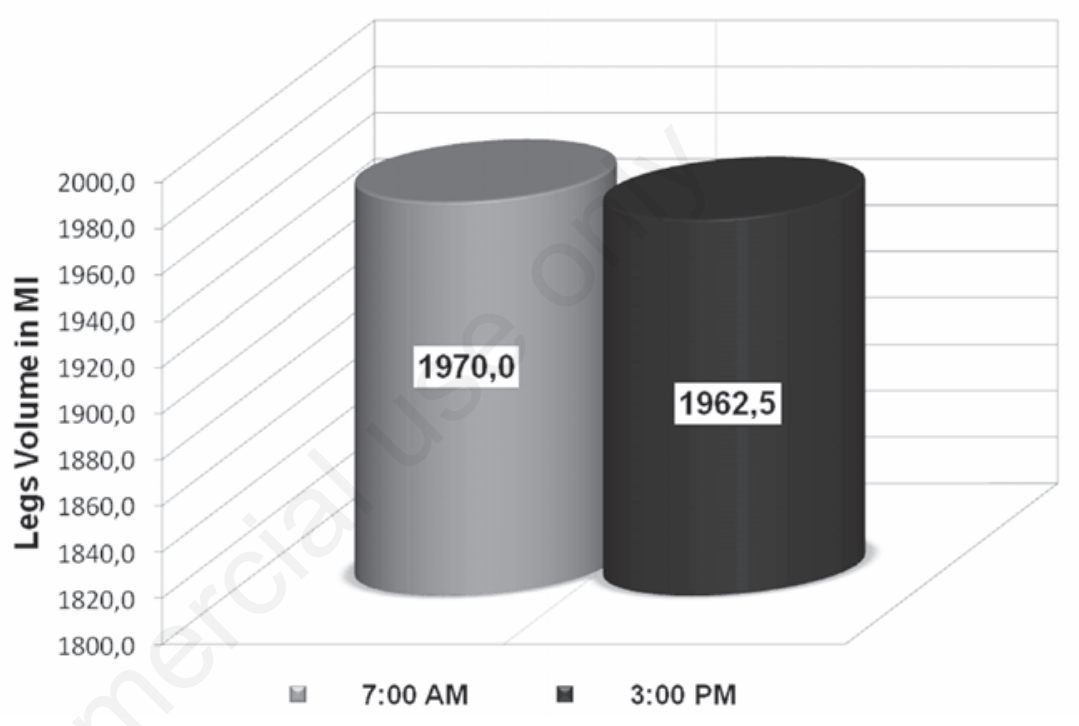

Figure 1. Right lower limbs (LL) volume slight decrease after $8 \mathrm{~h}$ of prolonged standing in an operating room with elastic stocking.

\section{LL Left Standing with Elastic Stockings}

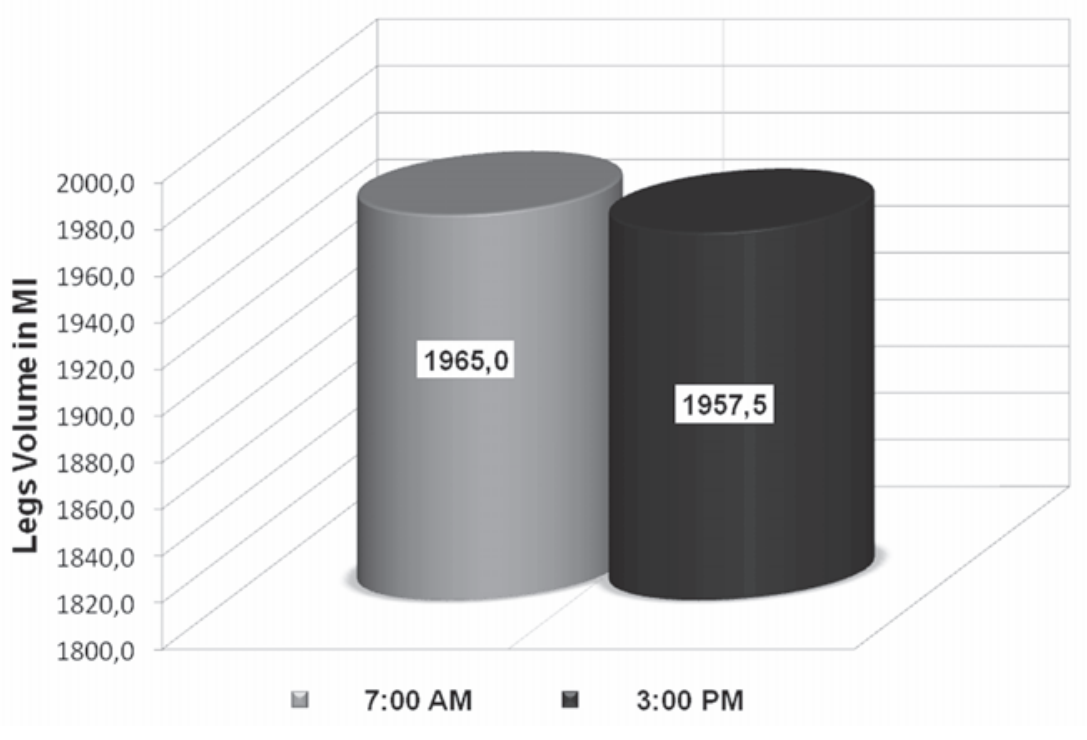

Figure 2. Left lower limbs (LL) volume slight decrease after $8 \mathrm{~h}$ of prolonged standing in an operating room wearing elastic stocking. 
decrease overtime, together with the linear correlation respect to the time spent under gravity, with elastic stockings, from morning to evening, respectively. Therefore, the time spent wearing the greater is the elastic stockings during the work in a standing position, the greater is the volume reduction, or rather edema decrease.

\section{Discussion}

Leg volume assessment by WP is an evaluation to be highly precise. ${ }^{26}$ Tape measurement of the leg circumference at different leg levels followed by calculation of leg volumetry with the mathematical formula of a truncated cone shows a very good correlation with WP measurements for both legs and arms..$^{27,28}$

Nevertheless, this method does not include the foot in the measurement and for this reason was not used in our study.

Legs can swell not only in patients with venous insufficiency but also physiologically in normal volunteers working in a prolonged sitting or a standing position. . $^{729}$

This natural phenomenon is exacerbated in those pathologic conditions causing a venous leg pump deficiency. These include ankle stiffness or paresis and valve damage. In these conditions, edema formation may become a clinical problem leading to induration and trophic disturbances of the skin. ${ }^{26,30}$

In healthy individuals the evening swelling is mostly asymptomatic and will disappear overnight. Nevertheless, unpleasant subjective feelings of heaviness and tiredness may be reported. $^{31}$

Venous hypertension of the lower limbs is the main mechanism involved in the onset and progression of CVI and leads to an inflammatory process in the microcirculation. Several mediators of vessel wall damage are activated, including reactive oxygen species which induce chemotaxis as well as leukocyte and platelet activation. ${ }^{32,33}$ Oxidative damage of the endothelial membrane and increased vascular permeability is followed by skin changes and edema. As these mechanisms work together, cell damage and venous stasis increases. ${ }^{32,33}$

In this condition, gravity leads to a venous pressure increase in the dependent regions of the body. According to the Starling's law, an increased venous pressure in the leg will lead to extravasation of fluid from the venules and to the edema formation. In a normal population, this so-called occupational leg edema quickly disappears whenever venous pressure is reduced because of walking or lying down and elevating the legs. ${ }^{7,29}$

The ordinary activity of people working for a prolonged period in standing has been shown to alter normal venous hemodynamic. Bishara et al. showed a significant decrease in venous refilling time in healthy women after their normal daily activity, requiring them to stand up for a minimum of $5 \mathrm{~h}$, with an abnormal venous refilling time in $21 \%$ of the examined limbs. ${ }^{34}$ Katz et al. had similar findings in normal subjects, they showed significant increases in venous filling index and significant shortening of venous filling time, comparing early morning with late afternoon..$^{35}$

By using duplex ultrasound scanning, Labropoulos found a significantly higher prevalence of venous insufficiency in a group of clinically healthy vascular surgeons, predominantly involving the greater saphenous system, compared with the control group of men with occupations not requiring long periods of standing. ${ }^{36}$

Compression therapy remains the best method for the treatment of CVI and elastic stockings remains the most widely used form of this therapy.

In a previous paper of ours, the same healthy population herein investigated under-

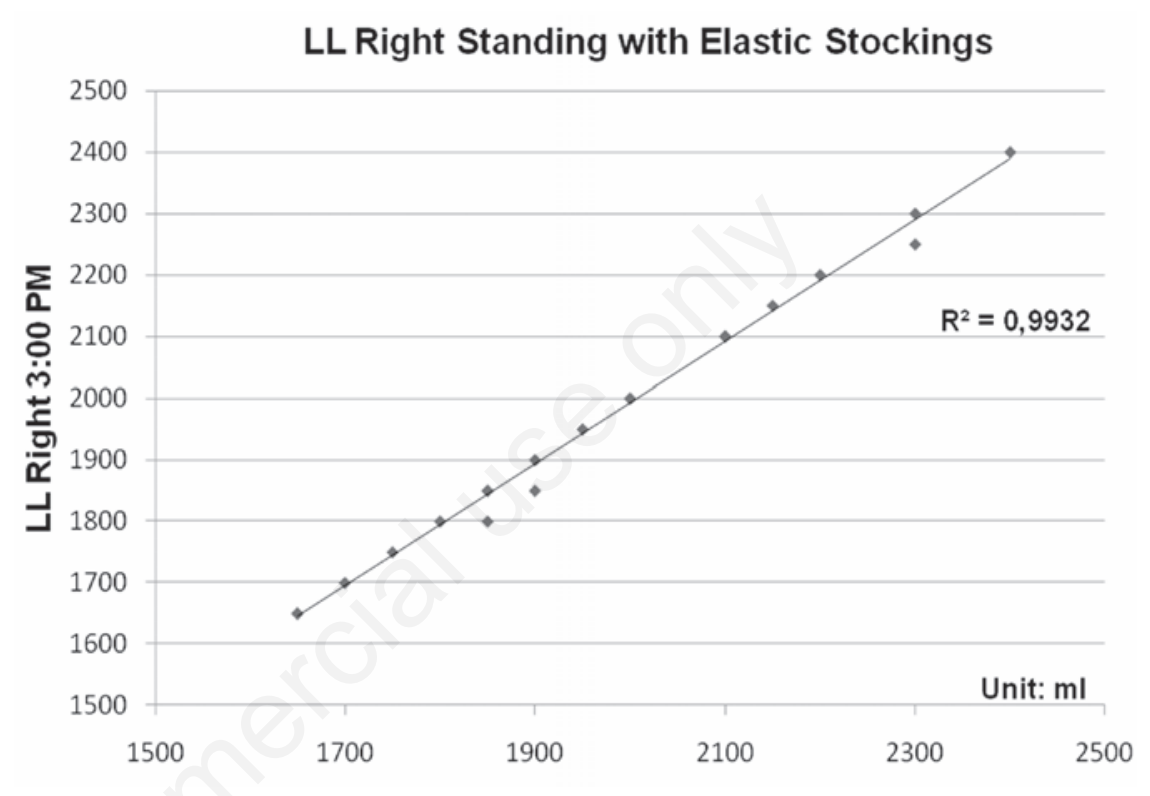

Figure 3. The correlation shown is that between volume at 7 a.m. and the volume at 3 p.m. in right lower limb (LL) in standing conditions with elastic stockings.

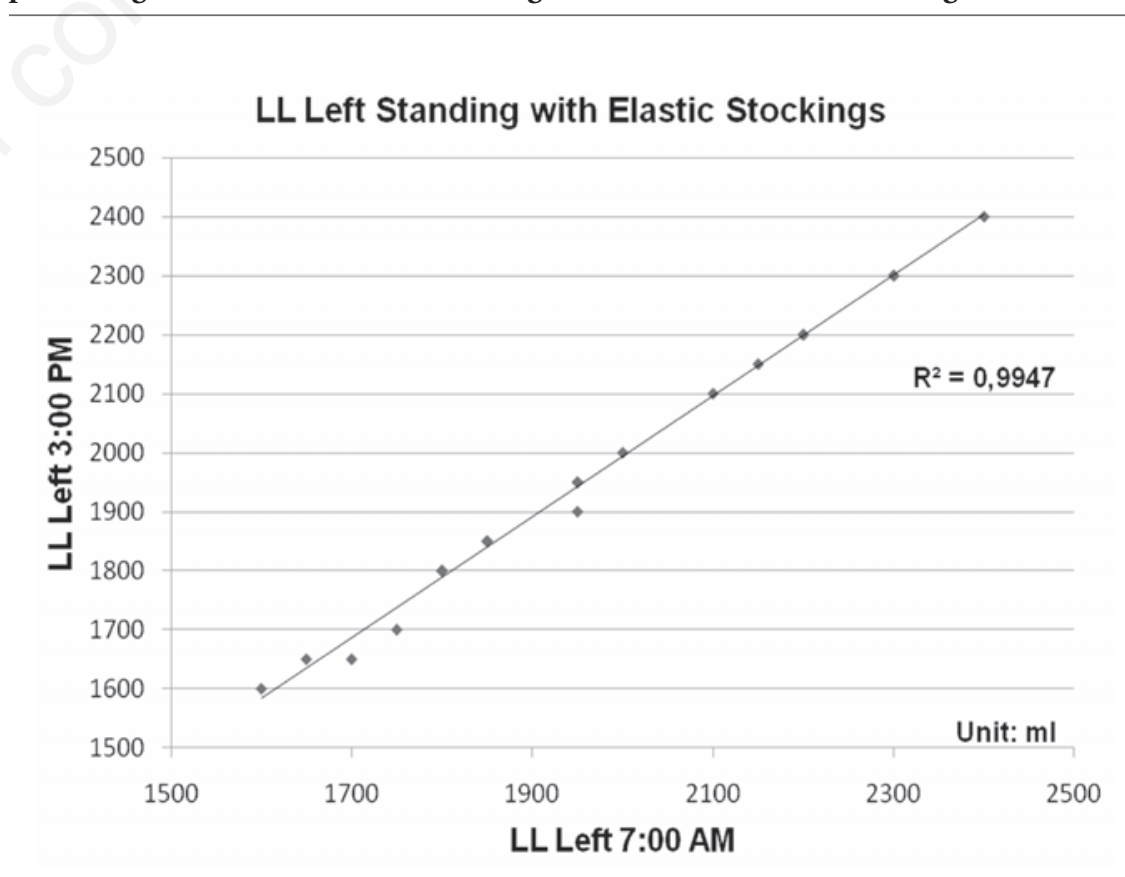

Figure 4. The correlation shown is that between volume at 7 a.m. and the volume at 3 p.m. in left lower limb (LL) in standing conditions with elastic stockings. 
Table 1. Comparison of the volume change in the lower limbs after a working day with and without elastic stockings. Comparison between the previous study without elastic stockings and this study with elastic stockings.

\begin{tabular}{lcccc} 
& \multicolumn{2}{c}{ Without elastic stocking } & \multicolumn{2}{c}{ With elastic stocking } \\
& Right leg & Left leg & Right leg & Left leg \\
7:00 a.m. & $1857.5 \pm 196.9$ & $1850 \pm 194.7$ & $1970 \pm 221$ & $1965 \pm 233.5$ \\
\hline 3:00 p.m. & $1945 \pm 209.6$ & $1940 \pm 216.2$ & $1962.5 \pm 220$ & $1957.5 \pm 239.7$ \\
\hline
\end{tabular}

went a prolonged standing in a homogeneous condition of hours exposure, daytime and temperature, but without elastic stockings use. Not wearing hosiery led to a significantly increased lower limb volume $(\mathrm{P}<0.0001){ }^{7}$ In the present study we investigated and evaluated the effects of elastic stockings (23-28 $\mathrm{mmHg}$ at the ankle) on healthy practitioner surgeons exposed to prolonged standing in the operatory room.

Differently from the vast majority of the literature on compression topic that is focused on CVI patients, our study is exclusively targeted to healthy subjects without CVI (HW).

Our results led us to point out that there is not just a simple pressure balance between the gravitational gradient and the elastic stockings exerted pressure, but rather that the last one is greater than the gravity gradient overload itself: in fact, we found lower volumes in the afternoon than in the morning.

This volume reduction, although not significant $(\mathrm{P}=0.08)$, suggested a statistical trend. It would be interesting to increase the population in a further investigation. More interestingly, the reduced leg volume was correlated with the time spent working with elastic stockings $\mathrm{R}^{2}=0.99, \mathrm{P}<0.0001$. In fact, the greater is the time spent wearing elastic stockings during the work in a standing position, the greater is the volume reduction, or rather edema decrease. This study shows that the use of elastic stockings can be helpful in the reduction of evening edema (Table 1). Moreover, the use of elastic stockings can reduce volumetric variations in the legs during work. Certainly the legs volume did not change and there was no increase.

The major limitation of our study is the height of $40 \mathrm{~cm}$ of the WP device. This height cannot change, therefore the measurement cannot be placed in legs that are longer than 40 $\mathrm{cm}$ from foot to calf.

The second limitation of our study is that this is a pilot study with HW with elastics stocking. In this study we do not have a control group. For the future we would make a cross over randomized study with and without the stocking.

Another bias to take into consideration is the possible variability coming from the different habit of the investigated subjects from the time in which they wake up and the distance covered to get to the working place.

In conclusion, our experiment demonstrates that the elastic stockings may effectively counteract the increased leg volume over time in workers who are exposed to a prolonged gravitational gradient. ${ }^{9,22}$

Age, gender, pregnancy, genetics are all risk factors for the CVI development, together with exposure to gravity for working reason. However, only the latter is a modifiable risk factor. In perspective, elastic stockings at work might correct one of the major risk factor for the development of chronic venous insufficiency.

\section{References}

1. Beebe-Dimmer JL, Pfeifer JR, Ewngle JS, et al. The epidemiology of chronic venous insufficiency and varicose veins. Ann Epidemiol 2005;15:175-84.

2. Krijnen RM, de Boer EM, Ader HJ, et al. Venous insufficiency in male workers with a standing profession. Part 1: epidemiology. Dermatology 1997;194:111-20.

3. Kontosic I, Vukelic M, Drescik I, et al. Work conditions as risk factors for varicose veins of the lower extremities in certain professions of the working population of Rijeka. Acta Med Okayama 2000;54:33-8.

4. Maurins U, Hoffmann BH, Lösch C, et al. Distribution and prevalence of reflux in the superficial and deep venous system in the general population - results from the Bonn Vein Study. Germany. J Vasc Surg 2008;48:680-7.

5. Lee AJ, Evans CJ, Allan PL, et al. Lifestyle factors and the risk of varicose veins: Edinburgh Vein Study. J Clin Epidemiol 2003;56:171-9.

6. Chiesa R, Marone EM, Limoni C, et al. Demographic factors and their relationship with the presence of CVI signs in Italy: the 24-cities cohort study. Eur J Vasc Endovasc Surg 2005;30:674-80.

7. Tessari M, Menegatti E, Gianesini S, et al. Assessment of lower limbs edema in healthy workers who are exposed to longterm gravity. Veins and Lymphatics 2013;1:e19.

8. Fiore R, Gerardino L, Santoliquido A, et al.
Reduction of oxidative stress by compression stockings in standing workers. Occupat Med 2007;57:337-41.

9. Buhs CL, Bendick PJ, Glover JL. The effect of graded compression elastic stockings on the lower leg venous system during daily activity. J Vasc Surg 1999;30:830-5.

10. Christopoulos DG, Nicolaides AN, Szendro G, et al. Air-plethysmography and the effect of elastic compression on venous hemodynamics of the leg. J Vasc Surg 1987;5:148-59.

11. Belczak CE, de Godoy JM, Ramos RN, et al. Rate of occupational leg swelling is greater in the morning than in the afternoon. Phlebology 2009;24:21-5.

12. Partsch H, Flour M, Smith PC, et al. Indications for compression therapy in venous and lymphatic disease consensus based on experimental data and scientific evidence. Under the auspices of the IUP. Int Angiol 2008;27:193-219.

13. Moffatt C. Variability of pressure provided by sustained compression. Int Wound $\mathrm{J}$ 2008;5:259-65.

14. Amsler F, Blattler W. Compression therapy for occupational leg symptoms and chronic venous disorders - a meta-analysis of randomized controlled trials. Eur J Vasc Endovasc Surg 2008;35:366-72.

15. Jonker MJ, de Boer EM, Adèr HJ, et al. The oedema-protective effect of Lycra support stockings. Dermatology 2001;203:294-8.

16. Belczak CE, de Godoy JM, Ramos RN, et al. Is the wearing of elastic stockings for half a day as effective as wearing them for the entire day? Br J Dermatol 2010;162:42-5.

17. Nicolaides AN, Cardiovascular Disease Educational and Research Trust, European Society of Vascular Surgery, et al. Investigation of chronic venous insufficiency: a consensus statement (France, March 5-9, 1997). Circulation 2000;14:126-63.

18. Porter JM, Moneta GL. Reporting standards in venous disease: an update. International Consensus Committee on Chronic Venous Disease. J Vasc Surg 1995;21:635-45.

19. Franceschi C, Zamboni P. Principles of venous haemodynamics. New York: Nova Biomedical Books; 2009. pp.12-30.

20. Coleridge-Smith P, Labropoulos N, Partsch $\mathrm{H}$, et al. Duplex ultrasound investigation 
assessment of edema and venous function. VASA 1973;2:4.

of the veins in chronic venous disease of the lower limbs--UIP consensus document. Part I. Basic principles. Eur J Vasc Endovasc Surg 2006;31:83-92.

21. Cavezzi A, Labropoulos N, Partsch H, et al. Duplex ultrasound investigation of the veins in chronic venous disease of the lower limbs--UIP consensus document. Part II. Anatomy. Eur J Vasc Endovasc Surg 2006;31:288-99.

22. Szuba A, Rockson SG. Lymphedema: classification, diagnosis and therapy. Vasc Med 1998;3:145-56.

23. Weissleder H. Diagnosis of lymphostatic edema of the extremities. Fortschr Med 1997;115:32-6.

24. International Society of Lymphology. The diagnosis and treatment of peripheral lymphedema: 2013 Consensus Document of the International Society of Lymphology. Lymphology 2013;46:1-11.

25. Thulesius 0, Norgren L, Gjöres JE. Footvolumetry, a new method for objective
26. Blazek C, Amsler F, Blaettler W, et al. Compression hosiery for occupational leg symptoms and leg volume: a randomized crossover trial in a cohort of hairdressers. Phlebology 2013;28:239-247.

27. Auvert JF, Vayssairat M. Volumetrics: an indispensable complementary test in lymphology. Med Intern 2002;23:388se90s.

28. Karges JR, Mark BE, Stikeleather SJ, et al. Concurrent validity of upper-extremity volume estimates: comparison of calculated volume derived from girth measurements and water displacement volume. Phys Ther 2003;83:134e45.

29. Mosti G, Partsch H. Occupational leg oedema is more reduced by antigraduated than by graduated stockings. Eur J Vasc Endovasc Surg 2013;45:523-7.

30. Mosti G, Picerni P, Partsch H. Compression stockings with moderate pressure are able to reduce chronic leg oedema. Phlebology
2012;27:289-96.

31. Partsch H, Winiger J, Lun B. Compression stockings reduce occupational leg swelling. Dermatol Surg 2004;30:737-43.

32. Coleridge-Smith PD. Deleterious effects of white cells in the course of skin damage in CVI. Int Angiol 2002;21:26-32.

33. Khodabandehlou T, Boisseau MR, Le Devehat C. Blood rheology as a marker of venous hypertension in patients with venous disease. Clin Hemorheol Microcirc 2004;30:307-12.

34. Bishara RA, Sigel B, Rocco K, et al. Deterioration of venous function in normal lower extremities during daily activity. J Vasc Surg 1986;3:700-6.

35. Katz ML, Comerota AJ, Kerr RP, et al. Variability of venous hemodynamics with daily activity. J Vasc Surg 1994;19:361-5.

36. Labropoulos N, Delis KT, Nicolaides AN. Venous reflux in symptom-free vascular surgeons. J Vasc Surg 1995;22:150-4. 